\title{
6. Laughing at Oneself: On the New Social Character
}

\section{by Jarno Hietalahti}

\begin{abstract}
Man goes to doctor. Says he's depressed. Says life seems harsh and cruel. Says he feels all alone in a threatening world where what lies ahead is vague and uncertain. Doctor says, 'Treatment is simple. Great clown Pagliacci is in town tonight. Go and see him. That should pick you up.' Man bursts into tears. Says,
\end{abstract}

'But doctor... I am Pagliacci.'

\section{Introduction}

This article discusses the philosophy of humor, with a focus on the phenomenon of laughing at oneself. The particular aim of this paper is to show that laughing at oneself is not as straightforwardly good or positive a matter as philosophers of humor have stated. I examine this cultural phenomenon in the light of Erich Fromm's thinking. In his written works Fromm is fascinated by the relationship between an individual and a society, as for example Gerhard Knapp $(1989,44)$ and Rainer Funk $(2014$, xiv) emphasize. I propose that the study of humor, in general, is a pertinent field in which to explore this duality: we all have a unique sense of humor, and still humor is typically shared. In the spirit of the Frankfurt School's Critical Theory, in this article I use philosophical concepts to analyze cultural phenomena. As mentioned above, the foremost interest lies in the case of laughing at oneself and the social level meaning of this tendency.

For conceptual clarity, in this article laughter refers to the laughter triggered by humor instead of, say, laughter resulting from nervousness. Humor is an umbrella concept for different kinds of amusing occasions. It covers, for instance, irony, satire, farce, the comic, and so forth. Of course, there are differences between various humorous genres, but examining those is a subject for another paper.

This article follows two traditional theories of humor: Incongruity Theory, and Superiority Theory. According to the Incongruity Theory, humor occurs when there is a conflict between our conceptions of or expectations about a situation, and the perceived reality of that situation. Another way of 
putting the theory is that in humor, there is an incongruity between cultural categorizations. The Incongruity Theory also states that when we find something funny, we find it funny only in relation to something else, and nothing is funny in and of itself. In contrast, the Superiority Theory states that we laugh when we feel ourselves superior in a certain way to others, namely the object(s) of our amusement (cf. Hurley et al 2011; Critchley 2004; Attardo 2008). So, I add, this is mainly an empirical point: every so often, when we laugh, we have observed some kind of flaw or fault or inferiority of the object we consider ridiculous. This theory does not withstand critical analytical examination, as will be shown below.

First, I will briefly clarify the phenomenon of laughing at oneself and the social demand for this trait. After that, I bring forth certain philosophical observations about self-ridiculing and highlight possible shortcomings of laughing at oneself. Then, I demonstrate why and how the presumed value of self-ridiculing is a problematic notion. The basic claim is that the ideal of self-irony is good, but by and large, a good idea has gone wrong in the contemporary Western world. Generally speaking, this article is written to point out that laughing at oneself is connected to recognition (Anerkennung), and that self-ridiculing can be a form of social pathology as well.

Humor can also be understood as a tool for gaining recognition. If I can make others laugh, I am recognized as a funny person. In everyday life, this is positive. Laughter, in a sense, brings people together; it is a kind of social glue. We tend to laugh in a similar manner in similar occasions, at least to a certain amount. Even though each one of us appears to have a unique sense of humor, humor is a widely shared phenomenon. Despite this general positive aspect of humor, in this paper I argue that there are also darker sides of humor. Humor can, for example, separate people. My claim is that there are at least two problems with laughing at oneself: 1) It is not clear what this self is which we laugh at. For this reason, the philosophy of self needs conceptual clarification if we are to understand what self-ridiculing actually means, and 2) self-ridiculing is not always a (morally) good thing.

\section{Laughing at Oneself and the Social Character}

Our culture is sympathetic to self-ridiculing. Professional critics always remember to mention if, say, a stand-up comedian or a cartoon laughs at everything - and at themselves. The latter is typically emphasized in a favorable tone. It seems to be that, to succeed in being funny, a comedian needs to mock herself as well as others. If she scorns just others, perhaps certain minorities, her humor is easily considered to be appalling. We tend to disapprove if some ill-mannered jester tells purely racist jokes (and is quite 
serious about them).

It is interesting that when a member of a minority makes a joke about her own group, the situation alters. For example, it is an altogether different case if a white male who supports National Socialism tells a joke about simpleminded black people, and if the storyteller herself is an African American. Also, every so often self-ridiculing is the best way to raise laughter - this is what stand-up comedians do from night to night. So, the basic cultural assumption is that laughing at ourselves is morally more acceptable and maybe even funnier than laughing at others.

In Western culture we need to show to others that we are capable of laughing at ourselves. There are several television shows that demonstrate this: for instance, roasting is popular in the United States, and also conquering Europe at a good pace. In a roast, an individual - typically a celebrity - is insulted and mocked by others. A presupposition is that the roastee should not be offended by the criticism but to take it all with a smile or laughter. To be roasted might even be considered as an honor. And this phenomenon is not just for celebrities. In a similar manner, as we live in the age of viral videos, people often upload their most humiliating clips to the internet. The message is that we are able to show the ridiculous sides of ourselves in public, and as a consequence, we do not take ourselves too seriously. As it happens, 'The Funniest Home Videos' is a popular format in television.

This trait of laughing at ourselves is also present in interactions beyond television or the internet. We make little jokes about our professions, our bodily features, our political thinking in everyday social gatherings; we are able to laugh when we stumble on the stairs in the dark, and so on. The capability of self-ridiculing and the ability to laugh at our own flaws can be considered as a socially recognized attribute.

Erich Fromm describes the meaning of this kind of social attitude with the concept of social character. The social character is a part of our character structure, and it explains how we relate to society and to other individuals. Essentially, social character makes people want to do what they have to do (cf. Fromm 1994, 275-296). Fromm writes:

I have always had this concept of the social character, by which I mean that human energy is one of the raw materials which go into the social process, but in a specific form of character traits which are molded by the conditions of the economic and social structure of a given society. (Fromm 2000, 27)

Fromm explains that the social character is 'the nucleus of the character 
structure which is shared by most members of the same culture' (Fromm 2006, 62). This character is shaped by, among other things, family, school and spare time. In general, social character describes how a group of people adapts to the prevailing economic, social, and cultural conditions. Of course, as conditions change through decades and centuries, the socio-economic demands alter. In short, social character is in direct relation to succeeding in a certain society (cf. Fromm 1994, 275-296).

Fromm's idea about the marketing-orientated character type appears to be relevant today, even though he described it in 1947. This character orientation is a combination of flexibility and independence. The core of the marketing personality is to be able to adapt to changing situations, and because of that, this personality lacks a strong center, which can be seen as disloyalty and even insincerity (cf. Fromm 2003, 49-60). Fromm's co-worker Michael Maccoby has developed Fromm's idea about this personality type and applied it to the modern day. According to Maccoby, this personality type predominates today in the form of the new social character type, which he calls the interactive social character (Maccoby 2014, 11).

Maccoby describes the new social character as follows:

At best, the interactive social character is both independent and collaborative. Interactives expect continual change. But they are not loyal to companies, and do not expect companies to be loyal to them. They are adept at forming relationships, but also at dissolving them. They have learned to adapt their personalities, their self-presentation, to different situations and audiences. (Maccoby 2014, 13)

The contemporary social demand to be able to laugh at oneself fits within this description. We must be flexible and alter ourselves as the situation dictates. As such, laughing at oneself signals that I do not take myself too seriously and am always able to perceive myself from a new perspective. This means that my profession, political thoughts or bodily features do not define me. For the interactives, as Maccoby calls this trait, it is easy to laugh at oneself: they do not commit themselves to anything nor does any single feature define them thoroughly. Someone with this kind of character finds it easy to laugh at any area of her life as laughing at those areas does not call into question her whole being. Rather, laughing at herself signals to others that she is mentally strong and self-confident. Neither her own nor others' laughter can hurt her. Here, having an ironical stance towards life can be interpreted as being an asset.

At a general level, social character is related to successful living. Still, 
it does not guarantee that an individual will live a happy or productive ${ }^{2}$ life, states Fromm. According to him, instead of just adapting to the social demands, we need to, among other things, relate to others and be rooted somewhere. Another central theme is that we have a need for an identity. Fromm stresses:

We have to be able to say 'I'. If we can't say 'I' we are crazy (...) Man today is confronted with the possibility of developing the sense of ' $\mathrm{I}$ ' but that means that he has developed his own creativity, his own productivity, he has to be he, he has to sense himself, experience himself as a center and subject of his own action. (Fromm 2010, 78)

\section{The Philosophy of Laughing at Oneself}

How does humor fit in life, generally speaking? Many philosophers throughout the millennia seem to have been quite skeptical and even bitter about humor and laughter. Thinkers from Plato (for example, in Republic (2003, 388e) and Laws $(2013,732$ c)) to Arthur Schopenhauer $(1887,281)$ have stressed how dark and unworthy our laughter is. Typically, according to Superiority Theory, we laugh when we see others as inferior to ourselves, and enjoy this feeling of superiority. In terms of Incongruity Theory, there is typically some kind of flaw present when we consider things to be funny. ${ }^{3}$

To overcome this morally problematic set up of highlighting others' flaws by laughter, some thinkers have emphasized the ability to laugh at oneself. At least, we cannot feel ourselves to be superior to anyone if we laugh at ourselves at the same time. The ability to laugh at oneself seems intuitively to be of high moral value. If I am laughing at myself, then, I cannot feel superior to others, as the Superiority Theory claims. Basically, I am not above my laughter and do not take myself too seriously. Self-ridiculing, in a way, clears the table from all separations.

The phenomenon of laughing at oneself has fascinated philosophers for centuries. Thomas Hobbes states that 'laughter is nothing else but a sudden glory arising from some sudden conception of some eminency in ourselves, by comparison with the infirmities of others,' which commits him to the Superiority Theory. But he also noticed that people have a habit of laughing at themselves upon certain occasions. For Hobbes, however, the object of this kind of laughter is not the present self. We might be able to laugh at some funny occasions that happened in the past - but if there is even a slight risk that we might make fools of ourselves by revealing something embarrassing via laughter, we cannot laugh (Hobbes 1640, ch. 9, par 13). 
Quentin Skinner, who has studied the traditional theory of humor and laughter, points out that Hobbes writes about self-ridiculing in his earlier books like The Elements of Law, Natural and Politic. But in Leviathan there is no room for this kind of laughter. Skinner ponders whether Hobbes considers the former self to be just like any other self (i.e. like the selves of others); then there is no need to distinguish these two. On the other hand, it is possible that Hobbes noticed that perhaps people really do not laugh at themselves as much as he had thought (Skinner 2004, 156-157).

Then again, for Sigmund Freud, it is quite obvious that the Superiority Theory will not stand because of the possibility of self-mockery. We can act as if we were crippled or stupid. When pretending, we might seem to be ludicrous, but our audience does not despise us and they do not condemn us as ridiculous. They do not feel superior to us because they know that we are just pretending (Freud 1916, 321).

Now, I have already mentioned two slightly different ways to laugh at oneself. According to Freud, we can play and present ourselves as a funny figure - and the audience laughs, even if not necessarily at our person. Instead, they might laugh with us. Hobbes, on the other hand, claims that we can laugh at ourselves when, for example, looking back and recalling something silly we did as a child. Still, there is a strong condition for this: we have to be sure that other people will not notice anything objectionable or anything else we should be ashamed of.

In addition, Charles Baudelaire notices that the sense of humor is in him who laughs and not in the object of laughter. However, there is an exception which flatters philosophers:

It is not the victim of a fall who laughs at his own misfortune, unless, that is, he happens to be a philosopher, in other words a being who, as the result of long habit, has acquired the power rapidly to become two persons at one and the same time, and can bring to bear on what happens to himself the disinterested curiosity of a spectator. But that is a rare gift. (Baudelaire 1956, 118)

There is a clear distinction between Baudelaire and Hobbes. Hobbes might place our former selves on the same level with others, but according to Baudelaire we are actually able to see ourselves in two different ways. There are at least a small number of people - philosophers - who are able to view their own fooleries from different points of view. Unfortunately, he does not further discuss this division of the self in more depth.

In any case, it seems that both Hobbes and Baudelaire see self- 
ridiculing as an exceptional ability. Even Freud writes that having a humorous attitude (more about this later on) towards oneself is a rare and precious gift (Freud 1928). However, for these thinkers, it appears that not every one of us is capable of laughing at ourselves.

In reality, nowadays many of us - and the comedians in the front row - are perfectly fine with self-mockery. Once a rare feature, this is a common ability nowadays. Christie Davies points out that the world has changed since Hobbes' days and the fear of being laughed at is not as central as it used to be. He writes: 'An ironic self-deprecating humor has become fashionable even on formal occasions in part because direct displays of pride are seen as not in keeping with the spirit of the age' (Davies 2009, 57). Other philosophers of humor, such as John Morreall (2010) and André Comte-Sponville (2001), claim that the ability to laugh at oneself is even virtuous.

The presupposed change of attitudes to self-ridiculing can be understood in the light of Fromm's social character. As social demands have altered through decades and centuries, so has the stand on humor and laughter. The current social character demands a new kind of flexibility or even fluidity, so we are more easily prone to ridicule ourselves now than we were in, perhaps, the $17^{\text {th }}$ century. Still the question remains: What actually happens, in a philosophical sense, when an individual laughs at herself?

Recall that according to the Incongruity Theory, nothing is funny in itself but instead, something is funny only when observed in comparison with something else. So, when I am laughing at myself, do I compare myself with me and reckon myself as ridiculous? This hardly appears as a plausible claim; moreover it is a silly statement.

Therefore, we have to see ourselves as ridiculous in comparison to something other than us. One option is to examine ourselves in relation to cultural categorizations, social values, common opinions, or such. In relation to this social level, we are able to see ourselves as ridiculous. But then again, are we actually laughing at ourselves? If, say, I joke about my homosexuality, my obesity or me being an overweight gay, I recognize that there might be something different about me than the general public. Now, as I understand the difference between me and the everyday Joe, I might be able to laugh at myself in this relation. But this does not guarantee that I actually laugh at myself.

\section{The Social Level in Self-Ridiculing}

Sigmund Freud and Simon Critchley have, in spite of all, made an attempt to clarify this social level within an individual in relation to self-ridiculing. In his journal article called Humour, Freud handles his topic as a special 
attitude and separates it from the comic and wit, which were his main targets in his studies considering jokes. ${ }^{4}$ Freud clarifies this with a distinction: in jokes we typically laugh at others, but in some cases we can have this humorous attitude also towards ourselves. Freud gives us an example about a criminal, who is going to be executed on Monday morning. As he walks to the gallows to be hanged, he looks up and says: 'Well, the week is beginning nicely' (Freud 1928, 1).

In this occasion the one who tells the joke raises his own humor. For Freud, the phenomenon is quite vague but valuable: 'Like jokes and the comic, humor has something liberating about it; but it also has something of grandeur and elevation, which is lacking in the other two ways' (Freud 1928, 2).

The grandeur element, for Freud, is about ego overcoming the real world - the ego denying that anything can wound it. Instead, it gains pleasure from external traumas offered by the world. For Freud, humor is a rebellious attitude (Freud 1928, 2). For the prisoner to be hanged, the aforementioned crack perhaps gives some kind of consolation. The inevitable is coming, and at least he cannot make the situation any worse by joking.

In the Freudian interpretation, when people laugh at themselves, we have to examine the relationship between ego and super-ego. If a person examines his own personality with a humorous attitude, he treats himself in a way as a child and at the same moment he relates to this child as an adult. In these occasions, amusement in itself is not that important; instead the purpose of the amusement is the essential thing. Via humor we can yell that even if the world appears to be dangerous and repressing, we can always joke about it (Freud 1928, 3).

For the sake of brevity we cannot go through Freud's psychoanalytical theories in more depth at this point. The central notion is, in any case, that with a humorous attitude and by laughing at ourselves we relate to ourselves like an adult relates to a child.

This 'child relation' is important for Freud also in his book about jokes (1916), but there is one obvious difference. By joking, we relate ourselves to the object of laughter as an adult relates to a child. For a child, her sources of suffering and points of interest are no doubt great and important, but the joker sees a child's grievances and delights in them as relatively small and unimportant when he compares them to an adult's worldly concerns. It is all about perspective. So, when we are able to laugh at ourselves, we see our own sorrows as quite insignificant. As such, we gain a new standpoint with regard to ourselves and perhaps even to the whole world. For Freud this wider perspective, the humorous attitude, is more distinguished than plain mocking of others. The dignity is perhaps obscure but there is something sublime about humor. 
Freud's interpretation of humor has inspired Simon Critchley who bases his vision of humane humor on it. For Critchley, the pattern is clear: because in jokes we laugh at others, and therefore see ourselves superior when compared with the objects of the joke, humor (as Freud uses the concept) is a morally superior option: 'laughter at oneself is better than laughter at others' (Critchley 2004, 96, 108).

For Critchley, humor reminds us about our own humbleness and limitations that are built-in in human life. But at the same time humor also functions as an anti-depressant. Critchley emphasizes that even though the super-ego is usually a hard master, in humor the case is altered. In humor the super-ego gives consolation to the ego and it does not punish the silly lad: 'This is a positive super-ego that liberates and elevates by allowing the ego to find itself ridiculous' (Critchley 2004, 101-103).

Roughly stated, the super-ego can be seen as identification with parental agency. It punishes misbehavior with feelings of guilt, and because of it, the individual strives to act in a socially appropriate manner. But in Critchley's interpretation the super-ego loosens its control. If we learn to laugh, especially at ourselves, then we may be able to understand ourselves and the world around us in a deeper way.

Critchley admires Samuel Beckett in the field of humor. Beckett has an exceptional capability to raise laughter that forces us to think. 'This is the highest laugh, the mirthless laugh, the laugh laughing at the laugh' (Critchley 2004, 49). This kind of laughter opens our eyes and causes us to drop our defenses, at least momentarily. And at this precise moment Beckett's ingenuity becomes clear: 'We realize in an instant that the object of laughter is the subject who laughs' (Critchley 2004, 49-50). This moment can even be frightening, and for Critchley, laughter is not always about pleasure. Instead, this feeling of pleasure might be mixed with the notion of uncanniness, and it is possible to be quite troubled by what we laugh at (Critchley 2004, 56-57).

All in all, we are melancholic animals, says Critchley, but also the most cheerful: 'We smile and find ourselves ridiculous. Our wretchedness is our greatness' (Critchley 2004, 111). He stresses that, nevertheless, we should not laugh at anything at any price. Critchley praises this humane humor that does not bring unhappiness but rather elevation and which is emancipating and comforting (Critchley 2004, 111). For him: 'True humour consists in laughing at oneself' (Critchley 2009, 230).

\section{Philosophical Problems of Self-Ridiculing}

So who has the last laugh? In Critchley's characterization there is something poetically comforting in laughing at oneself. For him and Freud, the 
relationship between the subject and object of laughter can be found in the light of internalized social demands, that is, in the relationship between super-ego and ego. Nonetheless, it is not too clear what the object of laughter actually is: if I laugh at myself, what do I consider funny?

In the English language there is a difference between laughing at someone and laughing with someone. This distinction is quite clear. Also, we may admit that in our everyday language it is not too strange to state: I can laugh at myself. But it is quite obscure if someone claims that she laughs with herself. This raises the questions: what is this ' $\mathrm{I}$ ' who laughs and what is the target, i.e. 'myself', who is laughed at? Philosophers of humor have not fully explicated this. But with Freudian interpretation and Critchley's thoughts, we can formulate that we are able to evaluate ourselves in relation to social estimations. As our super-ego (internalized social demands) sees the ego as a child, we observe ourselves in the light of cultural values and the like.

It can be interpreted that laughing at oneself also signals that I do not identify myself with, for instance, my poor eyesight and glasses, my inability to pronounce the alveolar trill or other features of mine. They are all my features, but they do not define me. In this way, I am able to detach myself from, for example, my limping left leg. This means that I do have a limping leg but I am not the limping leg. These are all my features but they do not actually define me.

This kind of viewpoint has not, presumably, been present throughout times and my assumption is that there are some cultural and historical differences at play. For example, in previous centuries people were more strictly determined by their social and economic class than they are today. In a sense, modern days are freer than earlier times, and the appearance of self-ridiculing can be interpreted as a sign of this freedom. But is there a cost for this freedom? If we do not identify ourselves with our professions, hobbies, bodies, thoughts, what is left? This can be interpreted to be a modern kind of alienation from oneself. Is there some kind of Cartesian soul lurking at the end of this line of thinking? My claim is that we are, after all, built on our thoughts, feelings, hopes, and so on. We cannot get rid of them.

If one thinks that she is thoroughly ridiculous wherever she is and whatever she does, she cannot take herself seriously any more. If one sees her own hopes and plans just as jokes, how can one act in the world any longer? It is as if this individual is in some way incongruous with herself, and does not have any self-respect. As such, the fun has probably already vanished and tragedy has taken over. And still, we have a cultural demand for self-ridiculing. We must be able to laugh at ourselves everywhere and at every moment. In the age of irony, the message is that nothing can be too 
serious for us - not even ourselves.

So, if the contemporary social character demands that we laugh at ourselves in this previous sense, it is problematic. It goes in line with what Michael Maccoby writes about the negative sides of the interactive social character. The interactives lack personality, integration and loyalty, and so: '[T]hey are connected to many and related to few if any. They are so used to adapting to different situations, of wearing different masks, that they are in danger of losing their center, the person behind the mask' (Maccoby 2014, 13).

Unlike what this trait demands, to live a full, rich human life, we need some kind of serious backbone, that is, a frame of reference and a baseline. This is the basis of Fromm's social philosophy. We have to have some values which are serious to us, and only after we find those values might we be able to compare some of our current opinions or ways of behavior, and see something funny about them (cf. Fromm 2010, 75-82). After that, hopefully, we can update our behavior and see the world slightly differently. A continually joking stance towards life, apprehending everything with humor and laughter, is practically impossible - especially if we are observing ourselves. We should not always try to find our own ridiculousness. This is exactly what Erich Fromm means when he writes about our capability to say ' $\mathrm{I}$ ' - and about the fact that the lack of this ability means insanity.

There are at least two problematic possibilities when we consider what may happen to the person behind the mask when we laugh at ourselves: 1) The person, ' $I$ ', is destroyed, or 2) the ' $I$ ' disappears from the sight of others, and possibly even from the joker herself.

Detachment from bodily features, thoughts and emotional expressions goes against what Fromm considers to be the basic needs pertaining to the human condition. This detachment presents dangers: our social relations may become hollow, we may no longer confront others in a sincere manner, and we might even become alienated from ourselves. This can be considered to be a personal and a social pathology. It has consequences even for reciprocal recognition: our interpersonal and intrapersonal relationships could become distorted. How can we face others and ourselves if we have no 'I'?

\section{Conclusion}

When someone implies that laughing at oneself is a good thing, no questions asked, we should be alarmed. It is an ideological statement, and in many cases false. So, if we convince ourselves that any kind of laughing at ourselves is the key to humane humor, the concept becomes ideological. My claim is that laughing at oneself does not justify anything by itself. Instead, 
we have to consider how this laughter relates to our attitudes and emotions, to our character and to others. In some sense, Simon Critchley appears to consider this laughing at oneself as the goal, the end, of humor. But in a Frommian sense, it should be seen as a starting point towards humane humor and recognizing oneself and others. In a certain respect, the most private side of humor - laughing at oneself - is actually strongly based on social estimations.

Critchley has it partially correct when he stresses that laughing at oneself is a better option than laughing at others. This, however, cannot be taken as a secure principle. This supposedly morally highest form of humor and laughter - self-ridiculing, belittling oneself, laughing at oneself - is not a foolproof way to save ourselves and others from all the possible miseries that can be related to fun and amusement. Let us consider Pagliacci, the poor clown in the opening joke of the article. Freud's and Critchley's position would not give him much consolation. Even though Pagliacci is extremely funny, and he probably knows that himself, he is deeply depressed. He needs to have some other reference point than just a notion about our twofold nature being melancholic and cheerful. The clown in the story is an outsider, beyond any traditional help. He does not belong anywhere and he is all alone in the universe. Laughter does not cure anything for him. I interpret this to mean that in a Frommian sense, he needs relatedness.

To understand the value of laughing at oneself and humor in general, we always need to consider also our social roles, cultural values, and positions in a society. Laughter does not resound in a vacuum; humor appears only in relationships, be they about conceptual categorizations, feelings of superiority, or something else. Nothing is funny in itself, but only when compared with something else.

The crucial problem is that we intuitively see laughing at oneself as the ultimate goal - that laughter is the end of this so-called humane development. But Frommian criticism demands that we cannot settle for this kind of laughter. Laughing at oneself does not actually state or guarantee anything. Laughter and joy are positive phenomena in general, but they can be used as a means to some problematic end - they might be, for example, a form of social dominance. A Frommian consideration might state that the contemporary laughing at oneself is actually just a mechanism of escape via which we might run away from boredom or ourselves. But this is not, in a humanistic sense, elevating. It is just a temporary cure for the symptoms, not for the disease itself.

I do not claim that laughing at oneself is always pathological. There is also a humane possibility in humor and in self-ridiculing. Examining this in a more profound manner is a job for another article but we can formulate 
some guidelines: by ridiculing ourselves, we might find our current situation to be ridiculous. Genuine laughter rejoices in the absurdity of the world and the limitedness of our concepts and categorizations. Still, this limitedness need not be daunting but can stimulate us to search for new ways to grow as human beings. All this, to be truly humanistic, is done in relation to ideals, which Fromm emphasizes. Laughter, in its highest form, can be a starting point for a joyful realization of the nature of things. In this way, humor can be radical. To be radical, we need to transcend the everyday level of thinking and language. That is, we need to challenge our current way of living. As such, humanistic humor is not restricted just to laughing at oneself. While we laugh at ourselves, we must be able to rejoice at the absurdity of the whole world. Fromm claims:

When I experience myself fully, then I recognize that I am the same as any other human being, that I am the child, the sinner, the saint, the one who hopes and the one who despairs, the one who can feel joy and the one who can feel sadness. I discover that only the thought concepts, the customs, the surface are different, and that the human substance is the same. I discover that I am everybody, and that I discover myself in discovering my fellow man, and vice versa. (Fromm 2006, 131)

This holds also for humor and laughter. According to Maccoby, who was a friend of Fromm, Fromm considered the sense of humor to be 'the emotional equivalent of a cognitive sense of reality' $(2009,143)$. So, given the absurd nature of the world and our limited categorizations in relation to it (cf. Fromm 1990, 77), we may well find ourselves as ridiculous. But this is just a starting point - not the end of humorous experience. Humor has the potential to reach beyond our everyday illusions. And yet, we should not claim this to be the purpose of humor. Humor has no purpose, even though it is easy to think that humor releases pressure, laughter prolongs life, joking keeps our minds lively, and so forth. But in a Frommian spirit, I claim that humor should not have any goals. If we use humor to achieve some extraneous purpose, it obscures the meaning of humor itself. In this sense, humor is not something to be consumed; it is an expression of the human condition in the world.

Jarno Hietalahti (jarno.hietalahti@jyu.fi) is a PhD student at the University of Jyväskylä, and he is currently finishing his doctoral dissertation in the Erich Fromm Institute Tübingen. His research focuses on Erich Fromm and the social philosophy of humor. 


\section{Bibliography}

Attardo, S. (2008) 'A Primer for the Linguistics of Humor' in V. Raskin (ed.) The Primer of Humor Research Berlin/New York: Mouton de Gruyter

Baudelaire, C. (1956) 'The Essence of Laughter' (trans. G. Hopkins) in The Essence of Laughter and Other Essays, Journals and Letters New York: Meridan Books

Comte-Sponville, A. (2001) A Small Treatise on the Great Virtues: The Uses of Philosophy in Everyday Life (trans. C. Temerson) New York: Metropolitan Books. Henry Holt and Company

Critchley, S. (2009) The Book of Dead Philosophers London: Granta Books

Critchley, S. (2004) On Humour London/New York: Routledge

Davies, C. (2009) 'Humor theory and the fear of being laughed at' in Humor: International Journal of Humor Research 22, Issue 1-2, 49-62

Freud, S. (1928) 'Humour' (trans. J. Riviere) in The International Journal of Psychoanalysis vol. 9, 1-6

Freud, S. (1916) Wit and Its Relation to the Unconscious (trans. A. A. Brill) New York: Moffat, Yard and Company

Fromm, E. (2010) 'Psychic Needs and Society' in E. Fromm Beyond Freud. From Individual to Social Psychoanalysis New York: AMFH, 75-82

Fromm, E. (2008) To Have or To Be? London/New York: Continuum

Fromm, E. (2006) Beyond the Chains of Illusion: My Encounter with Marx and Freud New York: Continuum

Fromm, E. (2003) Man for Himself. An Inquiry into the Psychology of Ethics London/New York: Routledge

Fromm, E. (2000) 'Human Nature and Social Theory' in Fromm Forum 4/2000 Tübingen: International Erich Fromm Society

Fromm, E. (1994) Escape From Freedom New York: Henry Holt and Company 
Fromm, E. (1990) The Revision of Psychoanalysis Boulder/San Francisco/Oxford: Westview Press

Funk, R. (2014) 'Foreword: Erich Fromm's Social psychological approach and its Relevance for Today' in S. J. Miri, R. Lake \& T. M. Kress (eds.) Reclaiming the Sane Society Rotterdam/Boston/Taipei: Sense Publishers, xixxiv

Hobbes, T. (1640) The Elements of Law Natural and Politic [online] Constitution Society, Accessed 14.10.2014, http://www.constitution.org/th/elements.htm

Hurley, M. M., Dennett, D. C. \& Adams, R. B., Jr. (2011) Inside Jokes. Using Humor to Reverse-Engineer the Mind Cambridge, Massachusetts/London, England: The MIT Press

Knapp, G. P. (1989) The Art of Living. Erich Fromm's Life and Works New York/Bern/Frankfurt am Main/Paris: Peter Lang

Maccoby, M. (2014) ‘Building on Erich Fromm's Scientific Contributions' in Fromm Forum 18/2014 Tübingen: International Erich Fromm Society

Maccoby, M. (2009) 'Fromm Didn't Want to Be a Frommian' in R. Funk (ed.) The Clinical Erich Fromm. Personal Accounts and Papers on Therapeutic Technique Amsterdam/New York: Rodopi, pp.141-143

Morreall, J. (2010) 'Comic Vices and Comic Virtues' in Humor: International Journal of Humor Research 23, 1-26

Plato (2013) Laws [Online] (trans. B. Jowett) The Project Gutenberg Literary Archive Foundation, Accessed 14.10.2014, http://www.gutenberg.org/files/1750/1750-h/1750-h.htm

Plato (2003) The Republic (trans. T. Griffith) Cambridge: Cambridge University Press

Schopenhauer, A. (1887) The World as Will and Idea. Volume II [Online] (trans. R. B. Haldane \& J. Kemp) Boston, Accessed 14.10.2014, https://archive.org/details/theworldaswill02schouoft

Skinner, Q. (2004) 'Hobbes and the Classical Theory of Laughter' in T. Sorell \& L. Foisneau (ed.) Leviathan after 350 Years Oxford: Clarendon Press 
Watchmen (2009) Dir. Zack Snyder, Paramount Pictures. Film.

\section{Endnotes}

${ }^{1}$ In different versions of the joke, the clown is called, among other, Carlin and Terrifini. This version of the joke is from the movie Watchmen (2009).

2 Fromm defines productivity as such: "The 'productive orientation' of personality refers to a fundamental attitude, a mode of relatedness in all realms of human experience. (...) Productiveness is man's ability to use his powers and realize the potentialities inherent in him." (Fromm 2003, 61)

${ }^{3}$ These two theories of humor and laughter are congruent with each other. We need to have some kind of general conceptualization which says how the world runs and what the so-called normal circumstances are. Then, when things surprise us and something odd happens, humor strikes in and we laugh. This is, of course, not the whole case: sometimes odd occasions might, for example, scare us or make us sad. But, as this is not a strictly analytical article about humor and laughter, I keep things simple and use these as a general framework for my analysis.

${ }^{4}$ Freud uses the concept of humor slightly differently than I do elsewhere in this article. 